\section{LA COMPAÑÍA DE ACERO DEL PACÍFICO, CAP. INSTAURACIÓN DE UN MODELO URBANO HABITACIONAL EN LA INTERCOMUNA DE CONCEPCIÓN}

Pablo Fuentes Hernández $z^{1}$ y Leonel Pérez Bustamante $^{2}$

\section{Resumen}

El desarrollo de la industria siderúrgica en Chile, imprescindible en la modernización nacional, ha acompañado históricamente asentamientos habitacionales para sus trabajadores, que originaron vínculos entre conjuntos e industrias y entre habitantes y jefaturas. Promediando el siglo XX la consolidación de la intercomuna de Concepción como zona industrial, y particularmente la aportación de la Compañía de Acero del Pacífico, CAP, originó importantes conjuntos habitacionales. Este trabajo examina las determinantes espaciales de aquellas relaciones y su contribución a la

\section{COMPAÑÍA DE ACERO DEL PACÍFICO, CAP. THE ESTABLISHMENT OF A HOUSING URBAN MODEL IN THE INTER-MUNICIPALITY OF CONCEPCIÓN}

\author{
Pablo Fuentes Hernández ${ }^{1}$ and Leonel Pérez \\ Bustamante $^{2}$
}

\section{Abstract}

The development of the iron industry in Chile, which has played a key role in the modernization of the country, has historically been associated with the emergence of housing settlements for workers, thus generating different housing-industry and dwellersupervisor relationships. By the mid-20thcentury, the consolidation of the inter-municipality of Concepción as an industrial center and the contribution made by Compañia de Acero del Pacifico -CAP-gave rise to important housing developments. This paper explores the spatial aspects of these relationships and their urban contribution. These projects saw 
imagen urbana. Estos conjuntos desplegaron nuevas tipologías arquitectónicas que, sobrepasando la ciudad histórica, instauraron unidades vecinales, alteraron el espacio público e incorporaron áreas verdes como articuladores espaciales. La investigación advierte cuatro tipologías: el encaje sobre la ciudad tradicional, la primera ciudad funcional (CIAM) en Chile, las unidades vecinales y los conjuntos segregados. El estudio revela que el paternalismo, el cooperativismo y la movilidad social son factores influenciados por el control, el poder y la identidad. Estos ordenamientos, fundados en principios racionalistas, aunque apropiados a una escala barrial, caracterizaron la intercomuna de Concepción hasta los años setenta.

\section{PALABRAS CLAVE: CONJUNTOS HABITACIONALES, AROUITECTURA MODERNA, PATRIMONIO INDUSTRIAL.}

Recibido: 12-09-2016

Aceptado: 23-01-2018

1 Chile. Docente, Departamento de Diseño y Teoría de la Arquitectura, Facultad de Arquitectura, Construcción y Diseño, Universidad del Bío-Bío. ORCID https://orcid.org/0000-0001-6628-6724. Correo electrónico: pfuentes@ubiobio.cl.

2 Chile. Docente, Departamento de Urbanismo, Facultad de Arquitectura, Urbanismo y Geografía, Universidad de Concepción. ORCID https://orcid.org/0000-0001-6661-6260. Correo electrónico:leperez@udec.cl. the emergence of new architectural typologies that expanded beyond the historical city, generating new neighborhood units that altered the public space and incorporating green areas to create a spatial link between these areas. This research identifies four typologies: adaptation within the traditional city, the first functional city implemented in Chile (CIAM), neighborhood units and segregated housing developments. It is observed that factors such as paternalism, cooperativism and social mobility are influenced by control, power and identity. These aspects, based on rationalist principles, although appropriated at the neighborhood scale, gave shape to the inter-municipality of Concepción up until the 1970s.

KEYWORDS: HOUSING DEVELOPMENTS, MODERN ARCHITECTURE, INDUSTRIAL HERITAGE.

Received: 12-09-2016

Accepted: 23-01-2018

1 Chile. Professor, Department of Design and Theory of Architecture, Faculty of Architecture, Construction and Design, University of Bío-Bío. ORCID https://orcid.org/0000-0001-6628-6724. Email: pfuentes@ubiobio.cl.

2 Chile. Professor, Department of Urban Planning, Faculty of Architecture, Urban Planning and Geography, University of Concepción. ORCID https://orcid.org/0000-0001-6661-6260. Email: leperez@udec.cl. 


\section{Introducción}

A la fecha, la historiografía de la arquitectura moderna en el siglo XX ha puesto la atención preferentemente en los procesos de introducción, desarrollo y consolidación de la arquitectura moderna atendiendo preferentemente a los autores, edificios individuales y las vicisitudes que les dieron cabida en el contexto chileno. En este marco, los conjuntos habitacionales han sido recientemente valorados a través de pesquisas particulares, por ejemplo, en tesis de pre y posgrado, en proyectos de investigación científica o bien como materia de ponencias en seminarios específicos. También ha habido revisiones sobre el ámbito institucional que escrutan la obra habitacional estatal del período (Castillo e Hidalgo, 2007; Raposo, 2008).

Este trabajo, cuyos casos de estudio habitacionales están cronológicamente situados a mediados del siglo XX, se apoya en la descripción del Plan intercomunal de Concepción de la época cuya acción comprendía 11 centros poblados, entre los que destacan Concepción, Talcahuano y San Pedro de Coronel (hoy San Pedro de la Paz), que es donde se emplazaron los conjuntos de la CAP impulsados por la Siderúrgica de Huachipato (Burotto, 1968, p. 70). Al respecto, la intercomuna de Concepción es una zona prolífica en la construcción de conjuntos habitacionales que de una u otra forma han determinado el crecimiento de la ciudad y una imagen asociada que prevalece hasta hoy. En particular, la revisión sobre la historia de los conjuntos habitacionales de la intercomuna de Concepción en el siglo XX ha sido hecha en artículos respectivos (Pérez y Fuentes, 2012). Este texto examinaba diversos conjuntos habitacionales erigidos al amparo de las decisiones estatales determinadas por las diferentes agencias del Estado desarrollando una visión panorámica del quehacer institucional y su papel en la intercomuna de Concepción.

Sin embargo, si se analizan estos hechos, vemos que el desarrollo industrial -con un siglo y medio de desarrollo en la zona- ha arrojado la construcción histórica de variados conjuntos levantados al alero de diversas factorías.

El caso de la vivienda minera de Lota y la producción carbonífera es prototípico en la construcción de la imagen de la ciudad industrial. En forma especial se reconocen de forma relevante dos hechos arquitectónicos coetáneos: el colectivo Chollín (Carbonífera Schwager, 1943-50) y la Villa Presidente Ríos (Siderúrgica de Huachipato, 1949), dan cuenta del impulso habitacional que realizó la industria en la región. Al respecto, el papel de la industria siderúrgica es un hecho especial en Chile, pues originó instalaciones habitacionales aledañas a las industrias que dieron cuenta de las primeras asociaciones entre siderurgia y habitación obrera. 
Del mismo modo, en la zona esta instalación fabril propagó una serie de realizaciones habitacionales, hasta ahora sin cotejo ni examen.

La hipótesis de este trabajo postula que el quehacer habitacional de la Compañía de Acero del Pacífico originó en la intercomuna de Concepción una serie de intervenciones que instalaron un modo de habitar arquitectónico y urbano inspirado en cuestiones de la teoría de la arquitectura moderna y cuyos resultados apropiaron en la escala intermedia una imagen y un uso contemporáneo adaptado y repetible. Su imagen asociada a la unidad vecinal se propagó por la zona instaurando un lenguaje prototípico.

El objetivo del trabajo es conocer el origen de los asentamientos siderúrgicos en Chile y, en particular, examinar los diversos conjuntos habitacionales originados al amparo de la CAP durante la segunda mitad del siglo XX en la intercomuna de Concepción y escindir los modos tipológicos en lo urbano y arquitectónico y sus repercusiones en el tejido urbano metropolitano.

En términos metodológicos, este trabajo examina tres ejes de desarrollo historiográfico: el primero, apegado a la historización del tema, indaga en el desarrollo siderúrgico en Chile, la descripción de sus alternativas y sus estrategias paternalistas sobre el desarrollo de la vivienda obrera asociada a su quehacer, perspectiva que incorpora un enfoque geohistórico correspondiente a desarrollos en territorios complejos. Aquí se han investigado las circunstancias históricas del proceso siderúrgico nacional, en especial las vicisitudes que propiciaron su desarrollo industrial y habitacional en la intercomuna de Concepción. En ese marco, la revisión bibliográfica de libros y seminarios ha insistido en develar las decisiones institucionales sobre la vivienda para trabajadores de la CAP, un tema escasamente atendido. El segundo, centrado en la obra habitacional de la Compañía de Acero del Pacífico, CAP, en la intercomuna de Concepción, aborda una clasificación tipológica que indaga sobre las constantes de su desarrollo urbano-arquitectónico a través de sus conjuntos específicos y la descripción detallada de sus opciones morfológicas. En este caso se ha recopilado y redibujado planos urbanos y arquitectónicos desde diversos archivos, que han sido la fuente para realizar análisis comparados. El tercero, un examen interpretativo, que necesariamente indaga en la articulación de la gestión política y el devenir de la movilidad social y sus vínculos con las lógicas del poder, el control y la identidad. En este caso se han realizado visitas y entrevistas no estructuradas para reconocer alternativas identitarias enmarcadas entre las estructuras espaciales y sociales. 


\section{Antecedentes de la modernización metalúrgica en Chile}

El desarrollo de la industria siderúrgica se asienta en las bases de la modernización en Chile. La Guerra del Pacífico de 1879 y la consecuente incorporación de la industria salitrera al crecimiento económico permitieron al Estado incrementar las obras públicas utilizando al hierro como material esencial en una serie de infraestructuras indispensables, como tendidos ferroviarios, estaciones, puentes, colegios, hospitales, etc. (figura 1). Entonces, la burguesía nacional no solventó este proceso, dejando al Estado como principal cliente y productor potencial. En 1886, Carlos Cousiño, empresario del carbón, contrató al ingeniero francés Charles Vattier (1840-1914) para buscar yacimientos de hierro. Tras su expedición fue el primero en señalar a la zona comprendida entre Concepción y Lebu rica en lignitos con posibilidades de transformarse en coque metalúrgico, y en consecuencia como la indicada para instalar una planta siderúrgica, recomendación que entonces no fructificó (Millán, 1999, p. 25). En 1886 surgen iniciativas privadas para erigir una siderúrgica con el Estado como encargado; quien condicionaba la incorporación de territorios sureños deshabitados y empleo calificado. Las garantías eran sobradas: exención de derechos de importación, libre traslado de minerales a los centros de consumo a través de Ferrocarriles del Estado y extensas concesiones sobre la exclusividad en la elaboración de materiales. Aun así el emprendimiento no tuvo éxito.

Tras varios emprendimientos infructuosos la siderúrgica francesa Schneider-Creuzot consiguió con el gobierno la promulgación de la ley 1.768 de 1905 con resultados ventajosos, que permitieron organizar en 1906, en París, la Societé des Hauts-Fourneaux, Forges et Aciéries du Chile (Sociedad Altos Hornos). Su primera actividad fue la adquisición del mineral El Tofo, a $70 \mathrm{~km}$ al norte de La Serena (Echenique y Rodríguez, 1990, p. 24; Cobo, 2007).

El gobierno a su vez impuso a la firma instalar una planta siderúrgica en el sur; así, la experiencia siderúrgica en Chile tiene su origen en los Altos Hornos de Corral, instalación próxima a la ciudad de Valdivia, que garantizaba transporte naviero y cercanía a bosques combustibles disponiendo el Estado de 50.000 hectáreas forestales para su explotación (Oviedo, 2011). La estrategia razonaba acercar el combustible maderero al centro mineral.

La planta se instaló en 1908, con asesoría francesa, belga y alemana; la mano de obra provenía principalmente de Chiloé. El alto horno se encendió en 1910, usando madera verde como material base combustible, una técnica que no tardó en quedar obsoleta. 


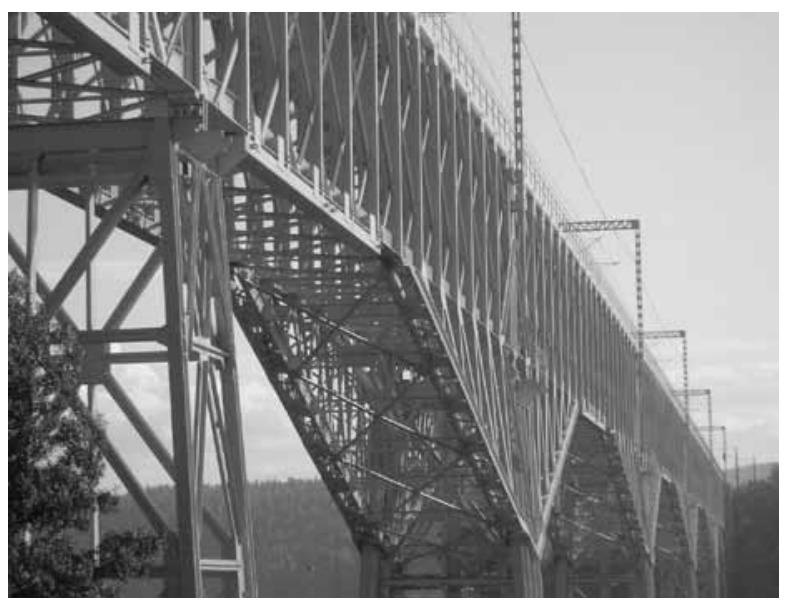

Figura 1. Viaducto del Malleco, 1872. Schneider et Cie. O Le Creusot. Fuente: Fotografía de Pablo Fuentes Hernández.

En 1908 las obras demandaron 170 operarios, cifra que aumentó a 400 más el personal administrativo. Se construyen diversas infraestructuras, además, de casas para obreros y empleados (Oficina de Turismo de Corral, s.f. Ver figura 2). Las habitaciones ocuparon cerros próximos a la industria y sus residentes vivían al amparo de los requerimientos patronales que impusieron su protección paternal y sin alternativas para la masa obrera. El obrero Braulio Cárdenas relataba:

"(...) Llegaba el trabajador aquí porque la compañía decía hagan su casa como puedan, entonces te daba permiso pa' que hagan tejuelas; se hacían las casas de tejuelas. (...) Crie mi chusma aquí y llevo harto tiempo viviendo solo acá (...) Claro, por conveniencia de los jefes, porque el jefe mayor que había aquí me preguntó si me iba a ir yo. Y yo le dije «no tengo pa' dónde irme, señor, porque mi padre nos crio en un fundo por ahí y de allá vinimos a trabajar aquí, puh. Y ahora no tengo pa' dónde irme, porque yo tengo un grupito familiar». Entonces cuando llegó el caballero me dijo: "Quédate con nosotros, nosotros te vamos ayudando en lo que sea posible»" (Oviedo, 2011).

La planta funcionó apenas 480 días arrojando un déficit imposible de sostener. El carbón vegetal producido con madera altamente concentrada en agua no era apto para las faenas siderúrgicas; la mala administración y el aprovechamiento de la empresa para obtener reembolsos del gobierno para sus pérdidas terminaron con el negocio (Echenique y Rodríguez, 1990, p. 25). La usina de Corral paralizó en 1911, aunque por su rentabilidad se respaldó la continuidad de la explotación de El Tofo.

Con estos antecedentes, la Sociedad Alto Horno arrendó en 1913 su yacimiento de hierro El Tofo a la Bethelem Chile Iron, subsidiaria de la Bethelem Steel Corporation, que ante la inminente apertura del Canal de Panamá concentró sus esfuerzos en la extracción de mineral de hierro para abastecer sus siderúrgicas en Estados Unidos. La compañía explotó el yacimiento pagando exiguos impuestos. Aquí surge otra instalación habitacional derivada de la siderúrgica en Chile, un campamento con viviendas en "corridas", aledaño a las instalaciones 


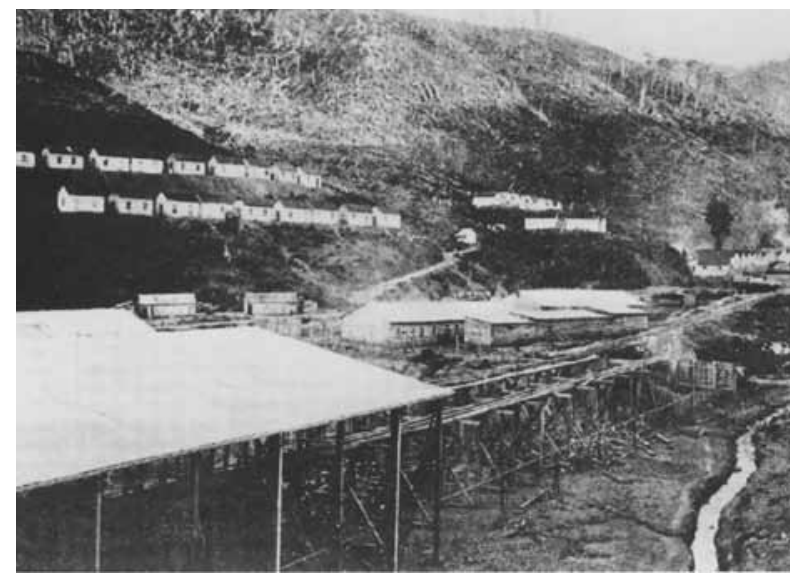

Figura 2. Altos Hornos de Corral. Habitaciones para los obreros. Fuente: Vattier, 1910.

en la falda del cerro (figura 3). Su ocupación estaba determinada por políticas paternalistas y sometimiento, manteniendo a los obreros en condiciones mínimas y miserables en medio de una población altamente estratificada -campamento americano, de empleados y obreros-, cuyos segmentos contaban con todas las instalaciones (escuela, hospital, teatro, iglesia, etc.) necesarias a su estrato.

El descubrimiento del salitre sintético a fines de los años veinte originó una grave crisis en el modelo chileno de exportaciones primarias. Su consecuencia inmediata fue la paralización de las industrias y una masiva emigración a las ciudades, con el consiguiente desempleo y deterioro de las condiciones de vida. El dramático panorama

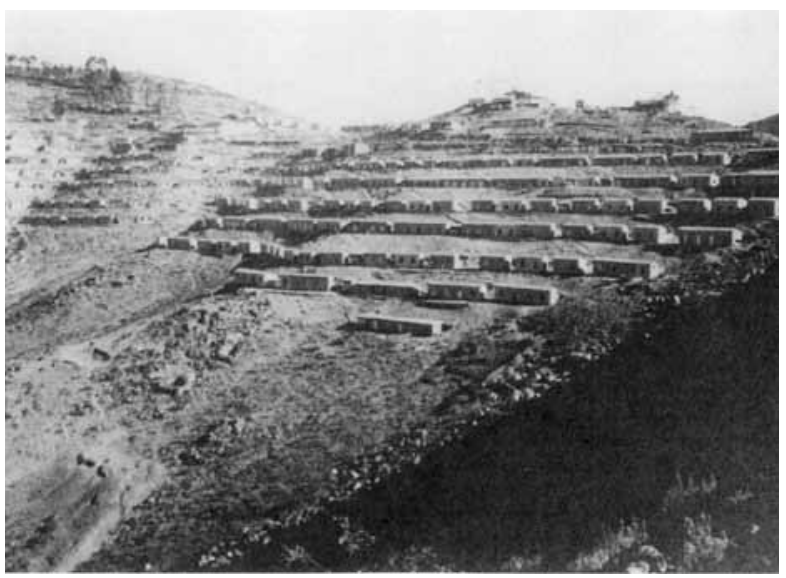

Figura 3. Vista a viviendas y cerros en el yacimiento El Tofo. Fuente: Colección Museo Histórico Gabriel González Videla.

signado como la cuestión social puso en entredicho el sistema gubernamental parlamentarista vigente, hundido en políticas insustanciales y sus partidos sordos al descontento general. El desajuste económico y desorden parlamentarista culminó con un golpe militar en 1924. Este gobierno castrense centralizó el sistema financiero, centralizó y fiscalizó el financiamiento público y creó organismos crediticios para el impulso de la industria nacional y del mercado interno. Este contexto inestable explica el largo periodo de inactividad de Altos Hornos de Corral entre 1911 a 1926.

En este marco, en 1924 el Estado y un grupo empresarial organizaron la Electro-Siderúrgica e Industrial de Valdivia, ESVAL, entidad mixta 
legalizada por Decreto nro. 79 de 1928, que compra y regenera en 1926 las instalaciones de Corral con el aprovisionamiento de mineral de El Tofo. El Estado comprometió el 80\% del capital suscrito e impuso a varios cargos de su directorio; asumió el control de calidad y cantidad de la producción de fierro y acero. Los privados, acusando un modelo intervencionista, paradójicamente demandaban apoyo estatal a su capitalización y la protección a los productos nacionales con políticas aduaneras (Echenique y Rodríguez, 1990, p. 39). Sin embargo, la inestabilidad de los gobiernos parlamentaristas extendidos hasta 1925, los movimientos obreros, golpes militares, la crisis bursátil de 1929, etc., agudizaron su mal funcionamiento debilitando el plan de modernización a la par que la crisis sociopolítica del país durante los años treinta.

El triunfo del Frente Popular en 1938, liderado por el presidente Pedro Aguirre Cerda (1879-1941), inauguró políticas estables con un consenso que abarcaba desde el conservadurismo liberal hasta el Partido Comunista. Las directrices del gobierno dieron impulso al desarrollo industrial, preocupación sistemática por el desarrollo del bienestar social y ampliación de las bases democráticas del sistema político. El gobierno debió enfrentar la situación socioeconómica agravada por el terremoto de 1939 y el comienzo de la Segunda Guerra Mundial; creó la Corporación de Fomento de la Producción, CORFO, que concertó la gestión estatal con la privada y el arranque de modernización industrial. Atendiendo al modelo de Industrialización por Sustitución de Importaciones, ISI, procuraba conseguir cierta independencia económica respecto del poder del centralismo económico internacional.

El presidente Juan Antonio Ríos (1888-1946), continuador político de Aguirre Cerda, impulsaba la acción del Estado y también el desarrollo del sector privado, en un ambiente de emergencia frente a la crisis de la economía agudizada por el conflicto bélico. Su mandato, caracterizado por el desarrollo productivo, auspició un modelo que aunaba estrategias industriales, capitalistas y estatales.

Según Echenique y Rodríguez (1990, p. 44) esta acción se puede interpretar como propia del capitalismo estatal, un modelo que corregía las deficiencias capitalistas propiciando mayor participación del Estado en la economía del país. Esta política profundizaba el proceso de sustitución de importaciones y aminoraba la inestabilidad de una economía basada en la exportación de materias primas.

En paralelo, el peso de la política norteamericana fue decisivo. Estados Unidos propagaba por Latinoamérica su política de "buena vecindad", alineando países del Cono Sur en respuesta a las vicisitudes bélicas europeas, pretendiendo influirles culturalmente a través de ayuda financiera y tecnológica que asegurara una dependencia. 
Sobre esta articulación política e institucional, Chile dispuso conseguir la instalación de una gran siderúrgica. En 1942 un informe recomendaba la zona de Concepción para instalar una planta, un sistema productivo, estudios técnicos, mano de obra especializada y la compra de maquinaria extranjera.

En 1944 Chile instala en Nueva York una oficina de CORFO, que coordinó los trabajos técnicos y financieros. El Export-Import Bank de Washington, banco norteamericano de comercio exterior, fue el principal acreedor de CAP. La entidad recomendó la contratación de Koppers Co., quienes realizaron el diseño general de la planta e instalaciones anexas. El trabajo cubría los aspectos administrativos (Echenique y Rodríguez, 1990, p. 11). Koppers fomentaba la competividad y calidad de las obras a índices norteamericanos y tutelaba a ejecutivos, jefes e ingenieros encargados. Asesoró la ubicación de la planta y estableció el sistema operacional, administrativo y contractual del estamento técnico norteamericano. Si bien se aceptaban los criterios de Koppers, la gerencia chilena resolvía las decisiones finales. En ese marco, CORFO compró la maquinaria a Estados Unidos.

En 1946 los trabajos contemplaron la contratación de técnicos norteamericanos especializados con amplias garantías laborales, y el adiestramiento de técnicos chilenos becados por CAP y CORFO. Este vínculo profesional derivó en la transmisión laboral de prácticas profesionales adecuadas a una siderúrgica moderna, pero también de modos sociales en la transformación y uso del espacio habitacional que derivaron en la implementación de nuevas tipologías arquitectónicas y urbanas que exploraban en la zona renovaciones del hábitat familiar contemporáneo. Al respecto, la instalación en espacios periurbanos, los trazados abiertos y libres -en oposición a la estructura de damero-, el uso prioritario de áreas verdes, la escala vecinal, etc., trasladaron a Concepción modos asociables al suburbio norteamericano.

\section{La intercomuna de Concepción y los conjuntos de la siderúrgica CAP}

En enero de 1939 un violento terremoto asoló Bío-Bío y Concepción. El desastre ameritó la construcción urgente de conjuntos residenciales con auspicio estatal, extendiendo a las provincias una modernización congruente con la arquitectura racionalista. Se privilegió así el emplazamiento de conjuntos habitacionales próximos a vías de tráfico interurbano y portuario de las redes productivas determinadas a partir del desastre. Las ciudades impulsaron el desarrollo manufacturero y el establecimiento de obreros y empleados. Concepción se transformó en el centro de un sistema tentacular articulando actividades políticas, administrativas, educacionales, comerciales y de servicios. 
En este marco, entre 1949 y 1965 la CAP erigió varios conjuntos para sus trabajadores (figura 4 , algunos se pueden ver en Castillo y Cuevas, 2015), entre los que destacan:

- Plaza Perú, Concepción, Aránguiz, Ovalle y Ugarte, 1941-1949.

- Villa Presidente Ríos, Talcahuano, S. Larraín García-Moreno, E. Duhart, 1949.

- Cerro Verde, Talcahuano (hoy Hualpén), Javier Rast, 1956.

- Villa Los Cóndores, Talcahuano, Eckart Lengerich, 1962.

- Villa Llacolén, San Pedro de Coronel (hoy San Pedro de la Paz), Augusto Iglesias y César Burotto en loteo; Jorge Le Roy y Rosa Aparicio en viviendas, 1962.

- Villa Acero, Talcahuano, Santiago Roi, Ricardo Hempel 1965.

- Villa Capataces CAP, Concepción, Santiago Roi, Ricardo Hempel 1965.

- Villa Collao, Concepción, Jorge Labarca, Boris Áptecar, Ruperto Bustos, 1965.

Este trabajo distingue cuatro grupos tipológicos que caracterizan las intervenciones urbanísticas y habitacionales de CAP.

\section{PLAZA PERÚ, UN ENCAJE CIRCUNSTANCIAL}

Una cláusula obligaba a CAP provisionar habitaciones para los técnicos norteamericanos y sus familias para sus estadías; se adquirieron así departamentos en el conjunto estatal Plaza Perú en Concepción, un boulevard en formación tras los estragos del terremoto de 1939. Ubicado al sur de la Diagonal Pedro Aguirre Cerda, fue un concurso convocado en 1941 por la Corporación de Reconstrucción y Auxilio obtenido por Aránguiz, Ovalle y Ugarte, que alteraba la traza ortogonal de la ciudad. Aquí, la Caja de la Habitación Popular emplazó un conjunto que reniega del urbanismo moderno con ideales conservadores. Su arquitectura, propia de un racionalismo temprano, insistía en bloques continuos con techumbre a la vista de tres niveles y portal a la calle para garantizar la circulación peatonal. Emplazado en torno a una plaza semicircular desde donde arrancaba la diagonal, determinaba articular la ciudad y la Universidad de Concepción (figura 5).

La CAP adquirió tres de los cuatro bloques en construcción para albergar a los estadounidenses. El proyecto, terminado en 1949, consolidaba un sector central de renovación urbana. Su diseño, más preocupado por una solución esteticista que por anhelos del urbanismo moderno, afianzó en la 


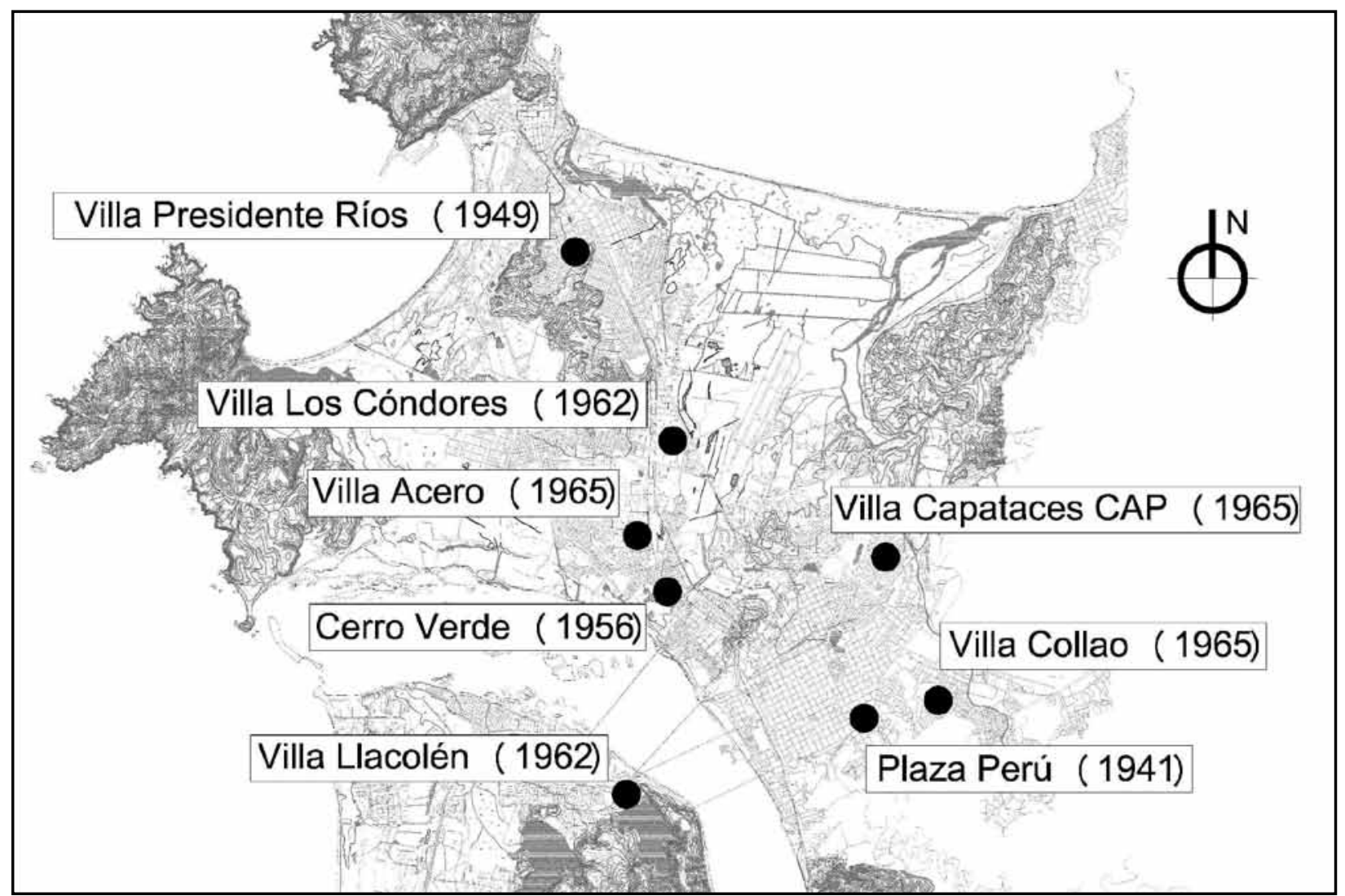

Figura 4. Plano ubicación conjuntos habitacionales de CAP en la intercomuna de Concepción.

Fuente: Plano de Pablo Fuentes Hernández, (dibujo de Pablo Miranda). 


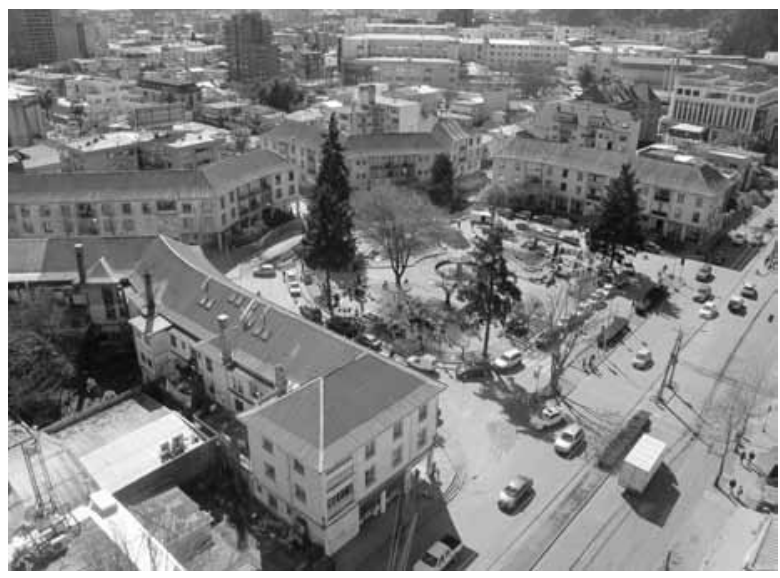

Figura 5. Plaza Perú (1941-49). Caja de la Habitación Popular. Fuente: Fotografía de Pablo Fuentes Hernández.

ciudad un lugar con carácter identitario. El sector, apartado de la usina, segregaba socialmente a los obreros norteamericanos en un área identificable, nueva y diferente. Por única vez un hábitat residencial de la CAP ocupó la ciudad tradicional en un lugar preferente.

\section{VILLA PRESIDENTE RÍOS. LA PRIMERA CIUDAD MODERNA}

Por las influencias de Eximbank y Koppers sobre la planificación de la siderúrgica, es admisible que las viviendas obreras debían tener un contenido correspondiente con un plan norteamericano de tal envergadura que hiciera correspondiente una nueva industria y un nuevo grupo de trabajadores a su cargo. El área escogida -el fundo Higueras- para un amplio y novedoso plan habitacional era aledaño a la siderúrgica siguiendo los patrones de la ciudad industrial; para el caso, la elección de Sergio Larraín García-Moreno y de Emilio Duhart como arquitectos recién asociados no parece aleatoria.

No se conoce con exactitud el papel de Larraín García-Moreno en el proyecto Villa Presidente Ríos; a pesar que el diseño duró varios años, sin embargo, el rol de Duhart es esclarecedor. En 1942 marchó a Estados Unidos obteniendo en 1943 un máster en Arquitectura en Harvard. Tuvo como maestros a Walter Gropius y a John M. Gauss. Trabajó con Konrad Waschmann en el General Pannel Corporation Prefabricated Housing y en el Programa de Guerra de San Francisco. Así, Duhart contaba con una sólida formación racionalista sobre las prácticas industriales y habitacionales propias del desarrollo posbélico.

Es necesario mencionar que el proceso de la instalación del Movimiento Moderno en Chile se consolidaba con hechos vinculados directa o indirectamente a Higueras. En 1946 se había publicado en Chile, aparentemente por primera vez en castellano, la "Carta de Atenas" (1946), y en 1947, Richard Neutra, presidente del capítulo norteamericano de los CIAM y al servicio del Departamento de Estado de los Estados Unidos, extendía la arquitectura 
moderna por Latinoamérica e invitaba a los chilenos a formar una filial en Chile, hecho acaecido en 1947 ("Filial chilena de los C.I.A.M.", 1947, p. 62). Firmantes de ese manifiesto habían sido Larraín García-Moreno, Duhart y Federico Oherens, arquitecto asesor de la CAP.

Asimismo, en 1947 visitaba Chile Paul Lester Wiener, socio de Josep Lluis Sert en Town Planning Associates, con amplio trabajo en Latinoamérica; en su paso, antes de dirigirse al VI CIAM en Bridgewater, fue invitado por la Escuela de Arquitectura de la Universidad de Chile a dar el 1 de agosto una conferencia sobre planificación urbana y la Ciudad de los Motores. Allí, Wiener trató las unidades vecinales como núcleos residenciales a escala humana que contenían los servicios y comodidades necesarias, separadas por áreas verdes, pero unidas a un centro cívico por vías de circulación separadas ("Paul Lester Wiener en Santiago", 1947, p. 18). Sobre la visita de Wiener a Chile, Eliash y Moreno (1985) afirman que entonces asesoró a Larraín García-Moreno, Duhart y Oherens en el proyecto de Las Higueras.

Por entonces una serie de sucesos impulsaban el desarrollo de las ciudades latinoamericanas. En 1947, el VI Congreso Panamericano de Arquitectos en Lima, primer encuentro continental después la conflagración mundial, tuvo como tema "Características y funciones de las unidades vecinales en las ciudades de América", donde Aludiendo al déficit habitacional, se examinaban soluciones para las ciudades latinoamericanas. Larraín García-Moreno presentó aquí la ponencia "La solución integral del problema de la vivienda económica en América" (Risopatrón, 1948, p. 46). También lo hizo en la comisión III Mario Pérez de Arce, uno de los primeros arquitectos en desarrollar académicamente el tema en la Escuela de Arquitectura de la Universidad Católica (Pérez de Arce, 1949, p. 37).

Así, a fines de los años cuarenta, las repercusiones de la ideología del urbanismo funcionalista en el desarrollo de la arquitectura residencial chilena tuvieron un eco decisivo.

La Villa Presidente Ríos (1949) fue una solución modelo. El proyecto, iniciado en 1949 y encargado a Larraín García-Moreno y Duhart, desplegó una ciudad obrera apropiando variados ideales de las teorías modernas. El plan fue aprobado en 1951 por la Corporación de Reconstrucción y Auxilio.

La villa, para 30.000 habitantes, ha sido reconocida como la "primera ciudad moderna en Chile" (Fuentes y Pérez, 2007; Fuentes, 2009) en tanto correspondió a una fundación de ciudad nueva sobre la que se aplicó en su diseño las recientes determinantes del urbanismo moderno de la ciudad funcional del IV CIAM de 1933, especialmente con la separación de las cuatro funciones a las que sumó las consideraciones de la unidad vecinal de Clarence Perry. Sus características están emparentadas con la ciudad-jardín privilegiando vínculos familiares y sociales. El trazado vial escindía 
el área en cinco partes (figura 6); cuatro correspondían a unidades vecinales para 7.500 personas, cuyo centro respondía al interés educacional del vecindario; cada una rescataba pasajes, plazas y jardines como argumentos que interpelaban la vida comunitaria. En el centro un núcleo cívico y de equipamientos articulaba la totalidad y aseguraba su funcionamiento autónomo. El proyecto, cuyos alcances no fueron del todo ejecutados, cumplía con aquellas cuestiones proyectuales de la urbanística contemporánea, a saber: separación de las funciones vehiculares de las peatonales, organización de los cuerpos rodeados de áreas verdes, división por macromanzanas y centros de abastecimiento en los núcleos, todas cuestiones opuestas al tratamiento compacto de la ciudad tradicional. El asentamiento admitió la descentralización urbana y modificó los principios CIAM constriñendo el espacio público.

Sobre este proyecto comparecen teorías urbanas que van desde Clarence Perry y la unidad vecinal (Sica, 1981, p. 175) a la ciudad funcional de la Carta de Atenas. Su resolución también responde a las críticas sobre urbanismo moderno doctrinal sostenidas por teóricos como Bardet, Mumford o Scharp. Fue coincidente con las reflexiones sobre el valor vital de los centros urbanos esgrimidas en los CIAM de posguerra. Su formación estuvo sujeta a un ambiente histórico específico que de varias formas impregnó su creación (Fuentes y Pérez, 2007).

Durante la década de 1950 y 60, cuando trabajadores norteamericanos retornaron a Estados Unidos y dejaron la usina funcionando, el proyecto se fue fragmentando en partes que desdibujaron la idea original. Este proceso se incrementó por la incorporación de nuevas agencias que en conjunto con la CAP gestionaron la ejecución habitacional del resto del proyecto, proceso que restó unidad a la ciudad obrera y que renunció al levantamiento del centro cívico.

Cabe afirmar que el proyecto representó la oportunidad única para Duhart y Larraín de desarrollar un proyecto integral que congregaba todas las escalas y todas las piezas del diseño, a la manera de una oportunidad heroica para todo arquitecto que se preciara de moderno en esa época; así, fue del pasaje a la calle y a la avenida, de la unidad vecinal al barrio y a la ciudad, de la casa al edificio, del núcleo al centro cívico, etc. De un modo u otro era la materialización de una nueva ciudad completa donde nada había antes. Un espíritu moderno y también norteamericano en la medida que la ciudad obrera era en realidad un suburbio. 


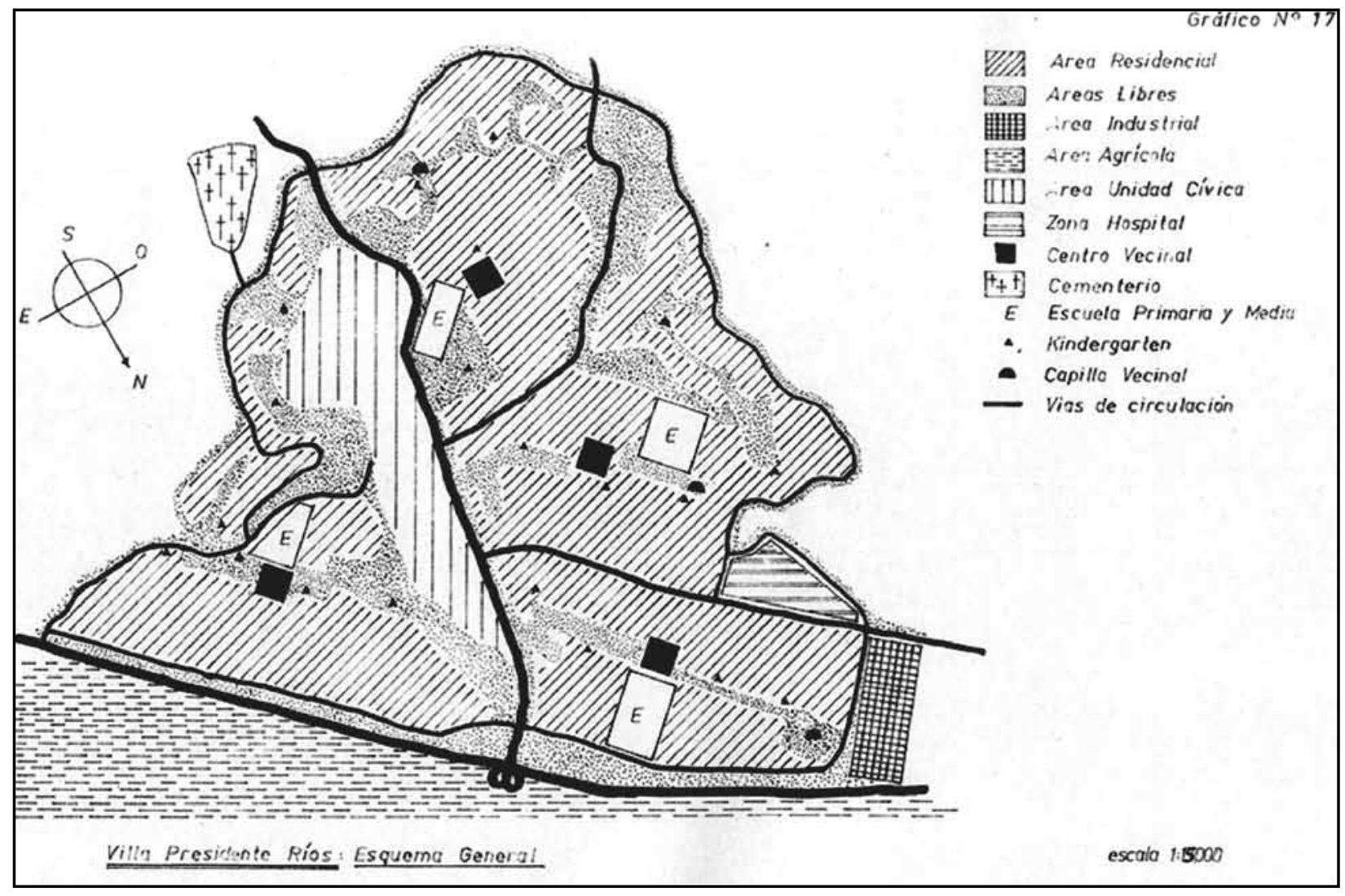

Figura 6. Seccional Villa Presidente Ríos, 1949. Arquitectos: Sergio Larraín García-Moreno y Emilio Duhart. Esquema general. Fuente: Archivo Claudio Sánchez. 


\section{UNIDADES VECINALES, FRAGMENTOS Y SUBURBIOS}

A partir de esta intervención, CAP auspició una importante cantidad de grupos residenciales, promoviendo la venta de viviendas sin intermediarios a sus empleados y obreros, o indirecta, en asociación con instituciones dedicadas a la acción habitacional como la Corporación de Reconstrucción y Auxilio y la Caja de la Habitación. La acción indirecta también consideró la gestión entre la industria, la Asociación de Ahorro y Préstamo y empresas particulares; y asimismo, acciones entre la industria y cooperativas de edificación. A partir de 1962, el reglamento de la CAP estableció préstamos en combinación con las Asociaciones de Ahorro y Préstamo y la Corporación de la Vivienda, CORVI (De la Fuente, Ramírez y Siegmund, 1983).

Así, en los cincuenta el modelo habitacional de CAP cambió. Nuevas estrategias de adquisición de vivienda y nuevas relaciones entre la industria y los obreros determinaron asentamientos más pequeños, fragmentarios, alejados de la planta, donde se minimizaron los argumentos modernos. Eran loteos hechos por arquitectos locales, de pocos accesos alojando en su centro un jardín público. Las zonas verdes contenidas por las viviendas fue un tipo predilecto. Las casas de una planta a veces pareadas fomentaban el volumen único rodeado de patios y jardines. Se omitieron edificios y centros cívicos, como mucho tuvieron equipamientos menores. La noción de ciudad mutó en barrio y, en consecuencia, el colectivo pasó a constituir una vecindad.

En esta conciliación entre industria, entidades estatales y particulares la CAP erigió varios conjuntos, entre los que destacan La Villa Los Cóndores, la Villa Capataces CAP, la Villa Acero, la Villa Collao y la Villa Llacolén. La mayoría admitió la descentralización urbana, mejoró los vínculos con áreas verdes y modificó los principios de los CIAM, sobre todo en cuanto a la reducción de las dimensiones del espacio público y al fomento de las relaciones comunitarias. Estas aspiraciones se manifiestan en el uso recurrente de la palabra villa para nominar estos conjuntos, término que connota un tamaño reducido de la población y sus viviendas, fuertes vínculos comunitarios, un cierto aislamiento respecto de los centros urbanos y la inserción en un medio natural preponderante. De este modo, estos factores caracterizaron los emprendimientos desarrollados por CAP entre 1950 y 1970.

Esos conjuntos se ubicaron preferentemente en Concepción, Talcahuano y San Pedro de la Paz, cuestión que sirvió para dispersar por la intercomuna no sólo unos conjuntos residenciales, sino que promovió la propagación una nueva imagen residencial asociada a casas bajas, rodeadas de áreas verdes, circulaciones controladas y la eliminación total de la calle corredor tradicional, estampa que a la postre entretejió los centros urbanos 


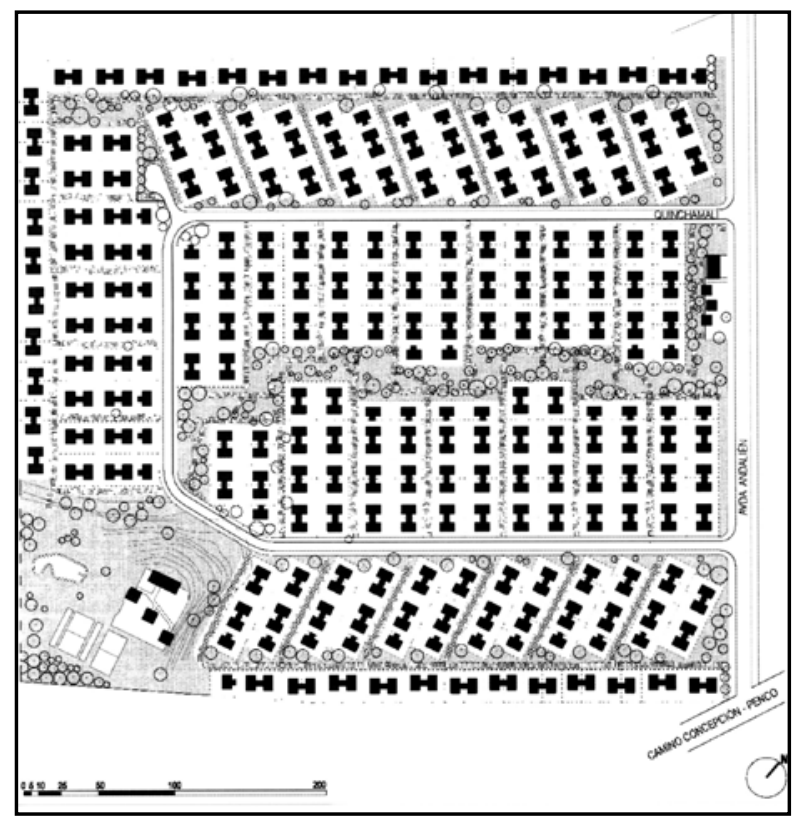

Figura 7. Villa Capataces CAP, 1965. Arquitectos: Santiago Roi y Ricardo Hempel

Fuente: Plano de Pablo Fuentes Hernández (dibujo de Pablo Miranda).

importantes de la intercomuna de Concepción y suturó en parte sus vacíos intersticios.

Estas poblaciones incorporaron argumentos urbanísticos que propiciaban la vida comunitaria. La Villa Capataces CAP (1965) se ubicó adyacente a la ruta que une Concepción con Penco (figura 7). Sus arquitectos fueron Santiago Roi y Ricardo Hempel. El proyecto se organizó como una unidad vecinal.
En su centro había una manzana atravesada por un jardín peatonal interior y rodeada por una avenida principal en "U", cuyos extremos sirven de acceso. La manzana fue rodeada por una franja también en "U" de viviendas y equipamientos. Consideró casas mayoritariamente pareadas, con antejardín y patio. La senda peatonal permitía conectar un pequeño centro comercial en el costado fronterizo con la vía principal y con una escuela y zona recreativa en la otra esquina del terreno. A partir de la avenida se dispusieron pasajes de penetración hacia las viviendas, perpendiculares hacia el centro y diagonales hacia la periferia, evitando así la continuidad espacial, y por tanto, admitiendo la formación de pequeñas vecindades. El loteo fue crítico con el urbanismo funcionalista, ya que privilegia la vida urbana restando calles de acceso y promoviendo pequeños pasajes y sendas verdes, superando los ideales macroespaciales y macroviales del urbanismo moderno. Era una posición más próxima al "sentido de vecindad" (Sharp, 1947, p. 103). Esta parcelación privilegia el espacio colectivo más aprehensible, alterando notoriamente la percepción del espacio público.

Por su parte, la Villa Acero (1965) es una gestión habitacional emprendida entre trabajadores de la CAP organizados en cooperativas y la sección de bienestar de la empresa (figura 8). El proyecto fue encargado igualmente a los arquitectos Roi y Hempel. Se emplazó en un terreno al poniente de la Av. 
Colón, afianzando la expansión poblacional por el camino a Talcahuano. Similar al caso anterior, se organizó una manzana en el centro del conjunto, de forma irregular, que también cruza una senda peatonal. Una calle principal, que nace y termina en el mismo lugar en Colón, rodea esta manzana. En particular, una calle en cul de sac se desprende de esta avenida para alcanzar el sector surponiente del terreno. Las viviendas de madera, pareadas y aisladas, se organizan en pasajes cortos perpendiculares a la vía principal sin continuidad espacial. En Colón se ubicaba el equipamiento público junto al acceso principal, y en el otro extremo de la senda peatonal interior se ubicaba la escuela en equidistancia relativa a las viviendas del conjunto.

\section{ESCISIÓN, SEGREGACIÓN Y ANTICOLECTIVISMO}

El emprendimiento más particular en este ámbito corresponde a Cerro Verde (1956), proyecto desarrollado sobre el loteo en comunidad de Eckart Lengerich para la directiva profesional de CAP formada por una quincena de personas. Aquí cada propietario escogió a diferentes arquitectos para el diseño de su vivienda, donde sobresalen arquitectos como Javier Rast y Víctor Lobos L., ambos del Departamento de Arquitectura de CAP. Destinado a otorgar viviendas a altas jefaturas de la empresa, es un condominio circular con un único acceso en cuyo centro hay una rotonda parcelada en cuatro sitios y en sus frentes lotes con viviendas de alto estándar (figura 9). Es un sector con ubicación estratégica tangente a una de las vías que unen Concepción y Talcahuano, con propiedades espaciales que fomentan la exclusividad, la privacidad, el aislamiento y la separación de los barrios aledaños. Es una intervención que niega ideologías colectivistas en el uso residencial del espacio urbano y que propicia el reducto aislado con áreas verdes protagonistas. Se trata de bungalows unifamiliares de un nivel, muy horizontales, generosos en superficie; erigidos en madera y albañilería de ladrillo con chimeneas de piedra que entonces denotaban su escalafón social, y techumbres a dos aguas. Cuentan con amplios patios y antejardines cuya tipología va adquiriendo particularidades según el deseo de cada dueño. Sus fachadas alternan grandes ventanales, que revelan las funciones sociales de la vivienda. Se trata, probablemente, de unos de los primeros emprendimientos habitacionales de la intercomuna que colonizaban la geografía circundante en Concepción prescindiendo de equipamientos añadidos y cofundadores de una tipología extendida entre las clases económicamente emergentes en la región.

Seguidamente, Villa Collao (1965) es una intervención que introduce cambios fundamentales. Dispuesta para profesionales medios de CAP es un conjunto diseñado por Jorge Labarca, Boris Áptecar y Ruperto Bustos, que incorpora valores semiprivados al espacio urbano. Si bien es un solo 


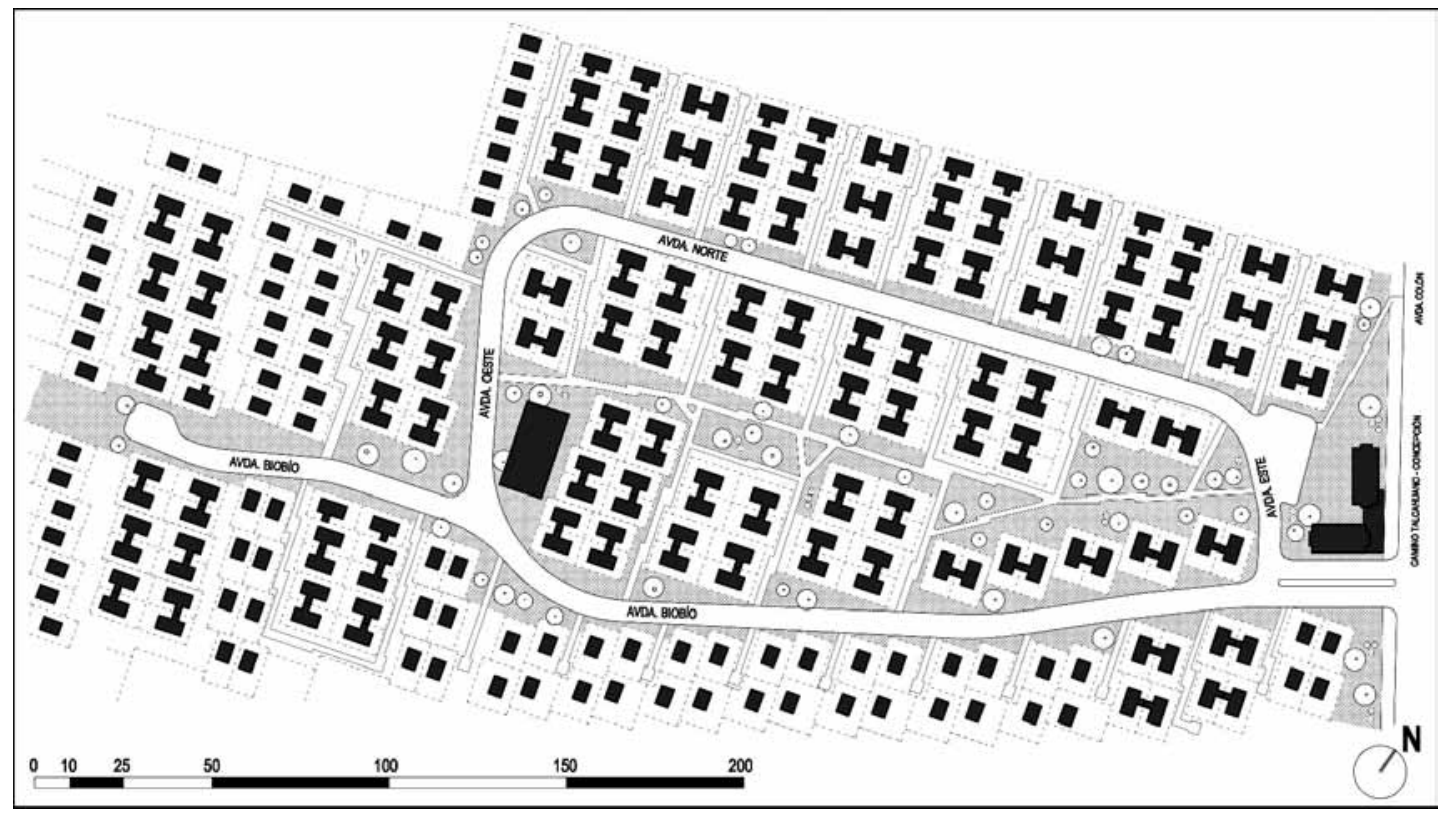

Figura 8. Villa Acero, 1965. Arquitectos: Santiago Roi y Ricardo Hempel.

Fuente: Plano de Pablo Fuentes Hernández (dibujo de Pablo Miranda).

conjunto ordenado en torno a una única calle, su parte plana se entrelaza con parcelamientos que rememoran la categoría anterior sobre fragmento y suburbio periurbano; no obstante, su parte en la falda del cerro Caracol, a la que se accede por un cuello espacial, inserta una imagen dada por la pendiente y por el ordenamiento habitacional frente a un único paño verde que en conjunto revela un uso levemente exclusivo del espacio habitacional (figura 10). Las viviendas desarrolladas en desniveles escoltan el espacio público que se torna característico y distintivo de la intervención. Es la primera vez que CAP establecía una suerte de segmentación del estrato medio para su personal experto en el espacio habitacional, el que igualmente omitía equipamientos complementarios. 
Figura 9. Cerro Verde, 1956. Arquitectos: Eckart Lengerich, loteo.

Fuente: Plano de Pablo Fuentes Hernández (dibujo de C. Bordones y Hwa Ye Qiu).
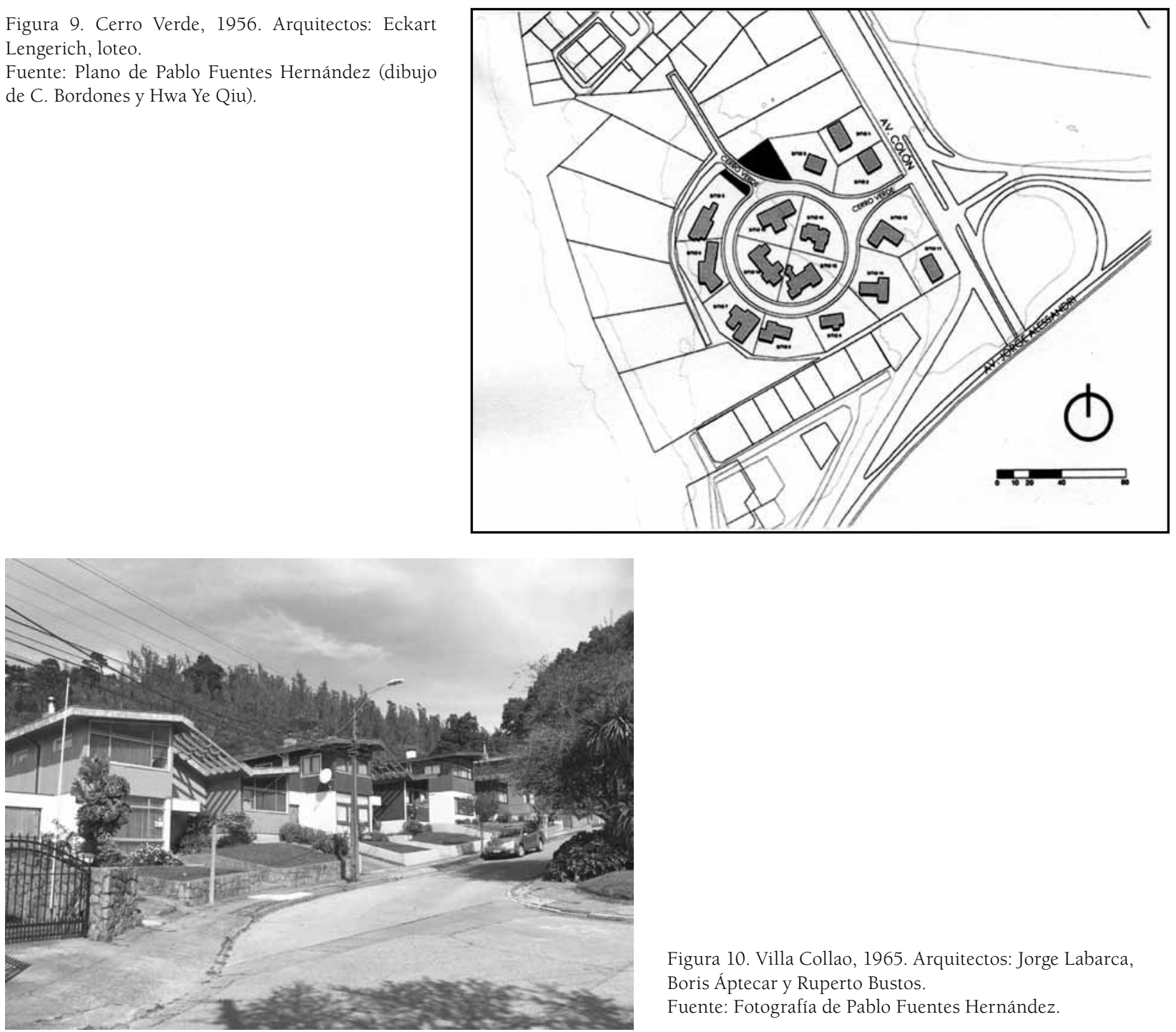

Figura 10. Villa Collao, 1965. Arquitectos: Jorge Labarca, Boris Áptecar y Ruperto Bustos.

Fuente: Fotografía de Pablo Fuentes Hernández. 


\section{Paternalismo, cooperativismo y movilidad social. Las lógicas del control, el poder y la identidad en la construcción del modelo urbano habitacional CAP}

A principios del siglo XX las siderúrgicas de Corral y El Tofo impusieron dentro de sus instalaciones operaciones espaciales que jerarquizaban las habitaciones de los distintos estamentos laborales y sociales en coherencia con las modalidades típicas del paternalismo industrial, esto es, que las viviendas de las jefaturas se ubicaban en terrenos privilegiados que transmitían el significado de poder y control sobre las viviendas del resto de los trabajadores a objeto de mantener estable el ideal productivo.

En El Tofo, la disposición era correspondiente con las distintas cotas topográficas del lugar, en este caso, el sector americano, el campamento de empleados y el campamento obrero estaban claramente escindidos ("Imágenes del origen del pueblo", s.f.). De este modo, en la cima más plana se ubicaban las casas del personal norteamericano y otras instalaciones como el hospital, el teatro y la iglesia, etc. El resto, los empleados y obreros chilenos, en las partes intermedias y en las faldas del cerro, respectivamente. De esta forma, se segregaba socialmente a las jefaturas de los trabajadores, ratificando el modelo habitacional de paternalismo industrial, esto es, separando a los trabajadores según su origen y estrato laboral para ejercer un control completo sobre ellos con el objeto de cautelar la producción. Las casas del "campamento americano", de construcción sólida, y ubicadas en la cima del poblado estableciendo su jerarquía espacial contaban con dos baños, agua caliente, pieza de servicios, bodega, jardín y estacionamiento. En esa cima, además, se encontraba una casa de huéspedes para los norteamericanos solteros o para visitas de la gerencia. El poblado, que tenía ley seca gran parte del año, contaba con una tenencia de Carabineros. Un dato más de esta segregación era que para los hijos de los obreros existía una sencilla escuela primaria para hombres y mujeres, que consideraba una educación obligatoria, mientras que los niños norteamericanos recibían una educación encargada a institutrices particulares o por un sistema de educación a distancia (Millán, 1999).

Para mediados del siglo XX el modelo de Industrialización por Sustitución de Importaciones, ISI, adoptado por el Estado chileno en el marco de un nuevo modelo de desarrollo, incluyó el bienestar social para la clase trabajadora. En ese contexto la promesa democratizadora del bienestar, auspiciada por la modernidad general y las nuevas formas de relación entre capital y trabajo, originaron mecanismos de movilidad social. La construcción del espacio que conformaba la ciudad obrera y, en 
particular, la capacidad económica de los trabajadores para acceder a una diversidad de viviendas, promovió nuevas respuestas al modelo (Brito y Ganter, 2015, p. 49).

En este marco, a partir de la década del cuarenta la CAP instauró otros modelos: primero el conjunto de bloques de departamentos de la Plaza Perú recibió a los técnicos norteamericanos y sus familias que montaban la siderúrgica. El conjunto articulaba el casco central de Concepción con la adyacente ciudad universitaria de Concepción, desarrollada magníficamente entre áreas verdes que permitían un espléndido entorno habitacional que privilegió al grupo, ratificando allí su estatus social propio del mundo de jefaturas.

Seguidamente, a fines de esa década, cuando la CAP inició un proceso habitacional propio para sus trabajadores, en concordancia con un modelo laboral cuya aspiración interpelaba el ascenso social, la empresa interpuso la construcción del espacio habitacional, colectivo en la villa y privado en las viviendas, ambos como herramientas de esa transformación social. Era objetivo de la empresa que sus trabajadores se transformaran en propietarios de sus viviendas, para los que permitió usar los diversos mecanismos públicos que admitieran el financiamiento, a saber: la Fundación de Viviendas de Emergencia, la Corporación de la Vivienda, CORVI; y la Caja de Previsión de Empleados Particulares. Así, la Villa Presidente Ríos, en los extrarradios de la ciudad y adyacente a la usina y como una forma de sostener esa dependencia social, incorporó variadas tipologías habitacionales para sus trabajadores, que iban desde las viviendas adosadas corridas, los departamentos en bloques, y en algunas zonas intermedias, grupos de viviendas aisladas para altos mandos. La idea era generar un barrio industrial, incluyendo y compartiendo bienes y servicios que materializaban una aspiración colectivista del hábitat residencial. Para ello, la empresa propiciaba el cuidado, aseo y mantenimiento del barrio, sus juegos infantiles y sus áreas verdes, etc. Asimismo, y para consolidar la intervención social de la empresa, esta instaló en la población una oficina permanente del Servicio Social de CAP, encargada de supervigilar el funcionamiento de centro de madres, jóvenes y vecinos, escuela de párvulos, centro deportivo, etc., mecanismos de relaciones que constituían un espacio laboral moderno y bien constituido (Brito y Ganter, 2014). Ratificando el sentido colectivista se instalaron en algunos sectores las viviendas para jefes, que eran de una tipología diferente al incorporar desniveles, mayor complejidad plástica y más superficies habitacionales. Su ubicación al interior de una de las unidades vecinales establecía el deseo por hacer del hábitat un sistema colectivo que mancomunaba trabajadores y empleados compartiendo por igual el espacio público.

Sin embargo, esta política, más transversal en término de mixturas habitacionales y sociolaborales, 
quedó trunca prontamente. Durante los años sesenta se impuso una lógica cooperativista que obligaba a los socios a participar de políticas de ahorro y postulación a beneficios, entre otros los habitacionales, que aspiraban igualmente a un mejoramiento en el escalafón social, originando una fructífera clase media con dependencia laboral, pero no espacial con la usina. Así, la falta de terrenos adyacentes a la usina determinó la ocupación de terrenos ubicados entre Concepción y Talcahuano, adyacentes a las principales vías de circulación y aptos para la construcción de nuevos barrios. Estos barrios, menos dependientes espacial, funcional y simbólicamente de la usina, se construyeron a la escala del barrio y no promovieron la mixtura social ni el ejercicio colectivista. De ese modo, la Villa Acero, la Villa Capataces CAP y Villa Los Cóndores y la Villa Llacolén determinaron no solo agrupaciones de viviendas con escasas variaciones tipológicas, sino también de menores dimensiones para trabajadores homogéneos en términos sociales, al tiempo que se reducía la construcción de equipamientos colectivos. Excepcionalmente, la Villa Collao logró articular dos estándares sociales muy similares, uno de ellos para profesionales de rango más alto ocupó la ladera del cerro Caracol, un lugar de significancia social más autónoma.

Del mismo modo, la industria estimó viviendas separadas para sus altos mandos y aquí el caso de Cerro Verde es paradigmático proponiendo una opción por la segregación socioespacial total. Como se ha dicho, aquí los chalets, diseñados por encargo de los propios residentes en un sistema urbano radioconcéntrico sin equipamientos, se emplazaban aislados y ocultos de la vista exterior, marcando distancia y prudencia de la ciudad en general y de la siderúrgica en particular.

Se eliminaba así el control espacial directo sobre las agrupaciones vecinales y en términos de dependencia el control paternalista, no obstante, quedaba reducido a fuertes vínculos identitarios con la siderúrgica en tanto empleador benefactor y promotor social. La noción de dependencia territorial, por su parte, se ampliaba a un sentido metropolitano.

\section{Conclusiones}

Durante el siglo XX la intercomuna de Concepción recepcionó varias estrategias habitacionales originadas por las industrias de la zona. Empresas como las carboníferas en Lota y Schwager, las textiles en Tomé y Chiguayante, la papelera en San Pedro de Coronel, la de hidrocarburos en Talcahuano, etc., produjeron modelos característicos. Las carboníferas privilegiaron la ciudad industrial, con habitaciones y servicios apegados a las industrias sometidas a un modelo paternalista de moralización y disciplinamiento en recintos cerrados con 
habitaciones designadas (Videla, Venegas y Godoy, 2016, p. 81). Las textiles, en Tomé y Chiguayante, ilustran un modelo de transición paternalista a la privatización institucionalizada, donde es visible el tránsito desde viviendas en hileras y casas de jefaturas inscritas en barrios autosuficientes y cerrados hacia un modelo extendido de casas aisladas o pareadas diferenciadas por tamaños. La papelera, por el contrario, privilegió la construcción de recintos habitacionales tutelados en enclaves ribereños.

Por su parte, la obra habitacional de CAP se revela como una suma de sucesos espaciales, que de una u otra manera parecen teñir el crecimiento tipológico de la intercomuna de Concepción. Los cambios formales, así como como la construcción de una identidad asociada al quehacer siderúrgico, sientan las bases de la cultura trabajadora pencopolitana.

Las intervenciones habitacional de CAP en Plaza Perú y Cerro Verde -ambas desarrolladas en forma radioconcéntricas- son emprendimientos que coinciden en el uso segregado del espacio público: si bien la primera inscrita en la ciudad de Concepción y la segunda en los extrarradios, ambas alejan a sus moradores de las instalaciones siderúrgicas $y$, en consecuencia, del ambiente trabajador identitario generado por la usina. En el mismo sentido, esta escisión de una élite profesional y económica sobre las clases trabajadoras instala un modo sociourbano de amplias consecuencias sobre el urbanismo regional.

Por el contrario, en el resto de los conjuntos habitacionales se revela la construcción física y espacial del concepto del suburbio, hasta entonces, inexistente en la zona. Se puede afirmar que se trata de un "modelo CAP de urbanismo" en la medida que adopta y adapta un modo espacial con reverberación social. Para el caso, la determinación de unidades vecinales, en situaciones urbanas intermedias, a escala humana, de tamaños controlados, con un uso que privilegia lo peatonal a lo vehicular, la plaza al parque, el pasaje a la avenida, aparece como un modo tipológico nuevo, cuyas raíces se asientan en la ciudad jardín europea para decantarse sobre un modo norteamericano que, no obstante apropiado, se desarrolla como suturas e hilvanes urbanos que tejen una red con capacidad intercomunal. Se establece así una relación que determina el espacio público de las diferentes partes de la ciudad remitido a pequeñas plazas, calles, pasajes, etc. Esta homogeneización se extiende a la configuración social de la ciudad en base a un proletariado urbano y a la clase media.

Finalmente, se observa que los conjuntos residenciales de CAP han sido agentes promotores del ascenso social en concordancia con el desarrollo del espacio público metropolitano, entendido este en la forma de pasajes, remansos, pequeñas plazas, 
etc. Asimismo, estos conjuntos han sido estructuras formales muy permeables, con generosos espacios libres y verdes de uso público, contribuyendo decisivamente a la formación de una sociedad urbana específica, fundamentalmente obrera, vinculada a un tipo de soporte económico mediano y a un tipo espacial más asociado a la escala del barrio que a la urbe. Ello explica que el desarrollo de un fenómeno identitario en torno a la siderúrgica extendido hasta hoy tenga antecedentes en el paternalismo, donde el control y el poder son atributos del espacio, hasta el cooperativismo, donde la identificación se enmarca en una dependencia más bien simbólica.

\section{Agradecimientos}

Agradecimientos al proyecto CONICYT/PIA SOC 1403, "Patrimonio industrial: formas de habitar colectivo en el sur de Chile. Aportes para su puesta en valor y recuperación integrada" y al Grupo de Investigación en Patrimonio de la Universidad del Bío-Bío, nro. 151701G/VC.

\section{Referencias bibliográficas}

Brito, A. y Ganter, R. (2014). Ciudad obrera: persistencias y variaciones en las significaciones del espacio. El caso de la siderúrgica Huachipato y su influencia en el Gran Concepción.
EURE 40(121), 29-53. https://doi.org/10.4067/ S0250-71612014000300002

(2015). Cuerpos habitados, espacios modelados: el caso de la siderúrgica Huachipato, 1940-1970. Historia 396, 5(1): 11-36. Recuperado de http://www.historia396.cl/index.php/ historia396/article/view/56.

Burotto, C. (1968). Planeamiento urbano en la intercomuna de Concepción. AUCA, (13), 59-72.

Carta de Atenas. (1946). Arquitectura y Construcción, (2), 29-32.

Castillo, H. y Cuevas, P. (2015). CAP como promotor habitacional en el Gran Concepción: estudio y análisis de seis conjuntos habitacionales (Seminario sin publicar). Concepción: Universidad del Bío-Bío.

Castillo, M.J. e Hidalgo, R., (Eds.) (2007). 1906/2006 Cien años de política de vivienda en Chile. Santiago: Ediciones UNAB.

Cobo, G. (2007). El Tofo. Imágenes tras la neblina. Coquimbo: Fondart.

De la Fuente, H., Ramírez, H., y Siegmund, S. (1983). Influencia de la Compañia de Acero del Pacífico en el desarrollo habitacional de la conurbación Concepción-Talcahuano (Seminario sin publicar). Concepción: Universidad del Bío-Bío.

Echenique, A. y Rodríguez, C. (1990). Historia de la Compañía de Acero del Pacífico S. A. Huachipato, consolidación del proceso siderúrgico chileno 1905-1950. Santiago de Chile: CAP. 
Eliash, H. y Moreno, M. (1985). Arquitectura moderna en Chile 1930 - 1960: testimonio y reflexiones. Santiago de Chile, Industrias Metálicas Chile.

Filial chilena de los C.I.A.M. (1947). Arquitectura y Construcción, (8), 62.

Fuentes, P. (2009). El desarrollo de la arquitectura moderna en Chile: apropiación, debate y producción arquitectónica, 1929-1970 (Tesis Doctorado, sin publicar). Universidad Politécnica de Madrid, España.

Fuentes, P. y Pérez, L. (2007) Vivienda obrera en Concepción. La Villa Presidente Ríos, primera ciudad moderna en Chile (pp. 85-106). En M.J. Castillo y R. Hidalgo, (Eds). 1906/2006 Cien años de política de vivienda en Chile. Santiago: Ediciones UNAB.

Imágenes del origen del pueblo minero El Tofo. (s.f.) Recuperado de http://www.museohistoricolaserena. cl/sitio/Contenido/Galerias/22950:Imagenes-delorigen-del-pueblo-minero-El-Tofo

Millán, A. (1999). Historia de la minería del hierro en Chile. Santiago de Chile: Universitaria.

Oficina de Turismo de Corral. (s.f.) El Castillo comienza a ser parte de Los Altos Hornos. Recuperado de http:// municipalidadcorral.galeon.com/

Oviedo, L. (2011). Altos Hornos de Corral. Los comienzos de la explotación maderera industrial a gran escala en la cordillera de la costa valdiviana. Recuperado de https://relatosdealerce.wordpress. com/2011/06/11/altos-hornos-de-corral-o-el-comienzo-de-la-gran-explotacion-maderera/.
Paul Lester Wiener en Santiago. (1947). Arquitectura y Construcción, (10), 18.

Pérez de Arce, M. (1949). Ciudad obrera de Huachipato. Arquitectura y Construcción, (16), 37-49.

Pérez, L. y Fuentes, P. (2012). Concepción: barrios que construyeron la ciudad moderna. Concepción: I. Municipalidad de Concepción.

Raposo, A. (2008). Estado, ethos social y politica de vivienda. Santiago de Chile: Ril.

Risopatrón, A. (1948). Carta al Sr. Ministro de Obras Públicas y Vías de Comunicación don Ernesto Merino Segura. Boletín del Colegio de Arquitectos, (13), 46.

Sharp, T. (1947). Urbanismo. Buenos Aires, Argentina: Ediciones Pingüino-Lautaro.

Sica, P. (1981). Historia del urbanismo. El siglo XX (2a ed). Madrid: Instituto de Estudios de Administración Local.

Vattier, C. (1910). La industria del hierro en Chile. Santiago: Imprenta Universo.

Videla, E., Venegas, H., y Godoy, M., (Eds.). (2016). El orden fabril. Paternalismo industrial en la minería chilena 1900-1950. Valparaíso: América en Movimiento. 